\title{
Mesenchymal Stem Cells and Stromal Vascular Fraction for Skin Rejuvenation
}

David Wolf, M.D. (Former Astronaut \& Chief of NASA stem cell research; Johnson Space Center, Houston, Tx.)

William Beeson, M.D. (Facial Plastics - Indianapolis, In.)*

John Rachel, M.D. (Facial Plastics - Chicago, Il.)

Greg Keller, M.D. (Facial Plastics -Santa Barbara \& Los Angeles, Ca)

William Hanke, M.D. (Dermatology - Indianapolis, In)

Jill Waibel, M.D. (Dermatology - Miami, Fl.)

Matt Leavitt, D.O. (Dermatology - Orlando, Fl.)

Michael Sacopulos, J.D. ( Medical Risk Mgt. - Terre Haute, In.)

*corresponding author: 10500 Cross Point Blvd., Indianapolis, In. 46256

FAX: 317-846-0722

E-mail: bill@beeson.com

Home: 3933 Kitty Hawk Ct.

Carmel, In, 46033

This is the author's manuscript of the article published in final edited form as:

Wolf, D. A., Beeson, W., Rachel, J. D., Keller, G. S., Hanke, C. W., Waibel, J., .. Sacopulos, M. (2018). Mesothelial Stem Cells and Stromal Vascular Fraction for Skin Rejuvenation. Facial Plastic Surgery Clinics of North America, 26(4), 513-532. https://doi.org/10.1016/j.fsc.2018.06.011 


\section{$\underline{\text { Introduction }}$}

The use of stem cells in regenerative medicine and specifically in facial rejuvenation is thought provoking and controversial. Stem cells have a natural ability to repair damaged tissue. They are inherent in most tissues of the body and function in a restorative capacity in many tissues such as the skin, where stem cells facilitate a rejuvenation of epidermal basal cell layers every day and in the intestinal tract, where mucosal lining tissues are replaced approximately every four days. In the case of degenerative diseases, these cells are not activated quickly enough to fully repair damaged tissue. The process of extracting, concentrating, and administering these stem cells have been shown in clinical trials to exhibit beneficial effects in many degenerative conditions. In addition, cellular therapies have shown great promise for skin rejuvenation, hair restoration, and many other clinical applications in other areas of medicine.

Surgeons have previously believed that damaged or diseased human tissue could only be replaced by donor transplants or, in select cases, alloplastic implants. Today there is increased emphasis on tissue engineering and regenerative medicine. Tissue engineering provides a more advanced approach in which organs or tissues can be repaired, replaced, or regenerated for a more focused treatment approach. Tissue engineering combines the principles of bioengineering, cell transplantation, biomaterial engineering, and surgery.

\section{$\underline{\text { Categories of Stem Cells }}$}


Stem cells possessed two important characteristics-they can renew themselves and they can give rise to specialized cell types. Essentially, there are two different classifications of stem cells embryonic and adult. Embryonic stem cells are isolated from the inner cell mass of blastocysts. Adult stem cells have been identified in many organs and tissues and reside in a specific area of each tissue called a "stem cell niche". There are three different types of adult stem cells pluripotent, multipotent, and unipotent. Pluripotent stem cells, such as embryonic or induced pluripotent stem cells, have the capacity to generate into tissue from any of the three germ layers. The risk for potential teratoma formation has impacted their clinical use. Multipotent stem cells, such as mesenchymal stromal cells, lack this negative effect and have the capacity to differentiate into a more limited number of closely related cells. Unipotent stem cells, although retaining the ability to self-renew, can produce only one cell type. This group plays a critical role in normal tissue homeostasis. The stem cells we are talking about for clinical therapies are essentially the multipotent type of stem cells which are derived from mesoderm origin.(1-3)

In the field of regenerative medicine, there is a need for a reliable source of stem cells in addition to biomaterial scaffolds and cytokine growth factors. Candidates include embryonic stem cells (ESCs), induced pluripotent stem cells (iPSCs), and postnatal adult stem cells. Embryonic stem cells and induced pluripotent stem cells have significant therapeutic potential, because of their auto reproducibility and their pluripotentiality. However, ethical considerations, cell regulations, and genetic manipulation limit their practical use. Postnatal adult stem cells are immunocompatible and are not fraught with ethical issues regarding their use. Postnatal adult stem cells can be obtained from bone marrow stroma, adipose tissue, 
dentition, skin, and a multitude of other tissues. They are termed mesenchymal stem cells (MSCs) and have adipogenic, osteogenic, chondrogenic, myogenic, and neurogenic potential.

Induced pluripotent stem cells

Ethical concerns associated with the use of embryonic stem cells spurred research efforts that would convert adult stem cells into pluripotent cells. In 2006, Shinya Yamanaka (Kyoto, Japan) altered the genes in specialized adult male cells to cause de-differentiation and return to an embryonic-like stem cell state. The mouse somatic cells were reprogrammed to the activation of a combination of transcription factors. The cells were termed "induced pluripotent stem cells" (iPSCs). Yamanaka was awarded the Noble Prize "for the discovery that mature cells could be reprogrammed to become pluripotent". In 2007 both Yamanaka and James Thomas (University of Wisconsin) independently developed techniques to reprogram human cells into induced pluripotent stem cells. (6)

Typically, viruses are used to genomically alter the cell to produce iPSCs. There were concerns that this manipulation could trigger the expression of oncogenes (cancer-causing genes). However, in 2008 techniques were discovered that removed oncogenes after induction of pluripotency. This opened the door for the potential use of iPSCs in human disease.(7) (8) Considerable research into anti-aging has focused on utilizing induced pluripotent stem cells to reprogram cell senescence. However, it has been noted that altering of induced pluripotent stem 
cells at a cellular level also allows for the stimulation of collagen synthesis. This potential for induced pluripotent stem cells to generate collagen has significant implications in the field of aesthetic surgery. (8)

\section{(Table or Side Bar)}

\section{$\underline{\text { Stem Cells }}$}

Stem cells have remarkable potential to develop into many different cell types.

Stem cells have two important characteristics:

1 - They can renew themselves

2-They can give rise to specialized cell types.

There are two types of stem cells:

1-Embryonic stem cells are isolated from the inner cell mass of blastocysts

2-Adult stem cells - have been identified in many organs and tissues and reside in a specific area of each tissue called a "stem cell niche"

The classic definition of a stem cell requires that it possess two properties:

Self-renewal - ability to go through numerous cell divisions while maintaining the undifferentiated state

Potency - capacity to differential into specialized cell types

Pluripotent - able to give rise to any mature cell type 
Multipotent -having the ability to develop into more than one cell type, buy only those of a closely related family of cells

Unipotent- can produce only one cell type but have property of self-renewal

(multipotent and unipotent progenitor cells are often referred to as stem cells)

In the past, there was no standard nomenclature and no standard, accepted method for identifying stem cells. For this reason, in 2006, the International Society for Cellular Therapy proposed a set of minimum criteria for identifying cells as stem cells. (9) These cells needed to adhere to plastic in culture and express certain surface molecules while lacking expression of others. In 2013, additional surface markers were added that should be expressed over $80 \%$ of the time on the surface of stem cells, while certain negative markers should be expressed on less than $2 \%$ of the cells. ((10) (11) The viability of isolated cells needed to exceed 70\% and have the presence of at least two positive and two negative markers for establishing a phenotype. In addition, the cells must possess the ability to differentiate into osteoblasts, adipocytes, and chondroblasts. The International Society for Cellular Therapy recommends calling these cells from any source "Multipotent Mesenchymal Stromal Cells".

Autologous (from the same organism) derived mesenchymal stromal cells require initial harvesting of tissue, which is usually via an invasive procedure. In the case of adipose tissue, this is usually by means of a direct surgical resection of adipose tissue or through liposuction aspirate. In the case of bone marrow derived tissue, this is by means of an invasive bone marrow 
biopsy. In addition, the tissue has to be processed, taking several hours in the case of supravascular fraction (SVF) and days to weeks in the case of culturing and expanding cells.

Allogenic (from multiple organisms within the same species) derived mesenchymal stromal cells raise immunomodulatory concerns such as graft vs. host disease (GVHD). In addition, there are concerns over communicable disease being transferred from donors to recipient.

In the case of adult stem cells, whether they are derived as autologous tissue from an individual patient or allogenically derived tissue from multiple donors, there is the concern of decreasing "stemness" of the cells. Many feel that over time, the potency or the "stemness" of the cells decreases, such that cells derived from older patients are less robust and therefore less clinically effective than cells derived from younger individuals. $(12,13)$

Pluripotent stem cells have significant therapeutic potential, because of their ability to differentiate into virtually any cell type. Pluripotent stem cells are isolated in three ways: (1) directly from human embryos (embryonic stem cells; ESCs), (2) from cloned embryos through somatic cell nuclear transfer (SCNT), or (3) from adult cells reprogrammed to a pluripotent state - usual by means of a virus inserted into the cell DNA resulting in genetic "reprograming" of the cell (induced pluripotent stem cells; IPSCs). Pluripotent stem cell work can involve the creation and destruction of embryos, and concerns have been raised regarding the potential for uncontrolled growth (such as teratomas). Their use has been complicated by not only significant technical challenges, but also due to serious ethical concerns. $(1,14,15)$

\section{$\underline{\text { Sources of Stem Cells }}$}


Stem cells obtained from adult adipose tissue ( adipose-derived stem cells or "ASC" or "ADSC" as they are commonly designated) are one of the most popular adult stem cell populations currently being used in stem cell research. This novel adult stem cell population isolated from adipose tissue was first described by UCLA researchers in 2002. Their multilineage mesodermal, ectodermal, and endodermal potential conceivably make the adipose-derived stem cell an alternate to pluripotent ES cells in clinical applications.(16) There are only two categories of stem cells: the embryonic stem cell (ES cell) and the postnatal stem cell (i.e., adult stem cell). The embryonic stem cell is derived from the embryo's blastocyst inner cell mass. The adult stem cell is derived from postnatal tissues and can include fetal derived stem cells and umbilical cord blood stem cells. $(2,3)(1)$

Mizuno and others have shown that cells obtained from human liposuction fat aspirates can also differentiate into adipogenic, osteogenic, chondrogenic, and myogenic cells in a lineagespecific culture medium. Such cells are termed adipose-derived stem cells (ASCs). $(15,17)$ Multiple studies have shown that there is no difference in mesenchymal stem cells obtained from bone marrow or adipose tissue in regard to fibroblast-like morphology, immune phenotype, colony frequency, and differentiation capacity.(18)

There are several of reasons to suggest adipose-derived stem cells for regenerative-based softtissue therapies. First is their multipotentiality, especially their proclivity for adipose differentiation. It is relatively simple to achieve a high level of adipose differentiation of adipose-derived stem cells in vitro, and many studies have developed methods to use them in vivo. Second, adipose- derived stem cells appear to potentiate angiogenesis and vasculogenesis. Third, surgeons have a significant familiarity and comfort level with the harvest and manipulation of adipose tissue. 


\section{$\underline{\text { Structure and Cellular Composition of Skin as it Relates to Dermatologic Aging and }}$}

\section{$\underline{\text { Regenerative Medicine }}$}

Mesenchymal stem cells derived from adipose tissue provide signaling to tissues which serves to adjust immune response, cell differentiation, migration, and enzymatic reactions. Adipose derived stem cells play a significant role in the maintenance of dermal and epidermal homeostasis.(12) To better understand this phenomenon, it is important to have a knowledge of dermatologic aging as well as skin structure and cellular composition as it relates to regenerative medicine.

Dermatological aging is a result of deficiencies in intrinsic cellular processes (DNA repair and instability, mitochondrial function, control over cellular metabolism, and control over cell cycle and apoptosis) and changes in epidermal homeostasis (integrity of extracellular matrix). These physiological changes in the skin are exemplified by decreased skin elasticity, reduced barrier function, development of skin rhytids, epidermal and dermal thinning as well as pigmentary changes. $(19,20)$ Stem cells residing in various stem cell niches in the hair follicle, in interfollicular epidermis and in sebaceous glands have been shown to play an important role in the maintenance of skin homeostasis.(21-23)

Our skin is the largest organ in our body and is responsible for a number of critical physiologic functions. It varies in thickness from $0.05-2 \mathrm{~mm}$ and is composed of 4 main layers. The outermost layer (stratum corneum) is 10-20 um. There is a highly hydrophobic layer which consists of 10-15 layers of nonviable cells called corneocytes. These hydrated corneocytes serve 
as a protective barrier and are held together by multiple lipid bio-layers composed of fatty acids, cholesterol and cholesterol esters, and ceramides. (24-26) The epidermis is the second layer and is subdivided into the stratum lucidium, stratum granulosum, stratum spinosum, and stratum germinatevum (basale). The epidermis is composed of keratinocytes which are in various stages of differentiation. Keratinocytes comprised $95 \%$ of the dermis. Those in the stratum terminal type layer are often referred to as "basal cells". While keratinocytes are the predominant epidermal cell, melanocytes, Merkel cells, Langerhans cells, dendritic T cells, and adipose cells are also present. In addition, multiple catabolic enzymes such as proteases, nucleotides, esterases, phosphatases, and lipases are present in the intracellular spaces. Mesenchymal stem cells residing in the skin are responsible for cellular signaling which regulates keratinocyte differentiation and influences other cellular functions to regulate homeostasis.(27-29) The basement membrane is attached to the dermis and provides a physical boundary between the epithelium and the dermis. It is rich in extracellular matrix proteins and growth factors. The dermis is composed of sebaceous glands, nerves, blood vessels, and hair follicles as well as adipose cells, mass cells, and infiltrating leukocytes.(30) The final layer is the subcutaneous layer (hypodermis) which is composed primarily of adipose cells, mesenchymal stem cells, blood vessels, and lymphatics.

Previously it was felt that the primary purpose of adipose tissue was to serve as a support structure and as a reservoir of energy in the form of triglycerides and as a storehouse for fatsoluble vitamins. However, numerous studies in recent years have demonstrated that adipose tissue provides significant influence on the cellular microenvironment by secretion of a widerange of bioactive factors with a diverse set of functions. Lipid metabolism and insulin sensitivity appeared to be influenced, as is the regulation of angiogenesis, immunomodulation, 
and inflammatory response. Adipose tissue secretory profile appears to influence tissue and organ homeostasis at the autocrine, paracrine, and endocrine levels.(31) Studies have also revealed that they also appear to be involved in mediation and management of keratinocyte and fibroblast proliferation migration in order to ensure epidermal and dermal repair. $(22,32,33)$ Thus, adipose tissue-resident mesenchymal stem cells can be viewed as "endogenous factories" producing trophic mediators able to support all of the functional skin layers to ensure skin homeostasis, regulation, and repair.(12)

ASCs have been shown to secrete several growth factors - vascular endothelial growth factor (VEGF), hepatocyte growth factor (HGF), fibroblast growth factor 2 (FGF-2), and insulin-like growth factor 1 (IGF-1). Travers and Spandu have reported on the role of IGF-1 in potentially reducing the incidence of skin cancer via its effect on keratinocytes. (34-37) Preliminary studies by the author indicate that IGF-1 may also play a role in reducing cutaneous rhytids.(38)

Gimbel et al have shown that ASCs introduced into injured tissue results in secretion of cytokines and growth factors that stimulate recovery in a paracrine manner. Gimbel points out that ASCs modulate the "stem cell niche" of the host by stimulating the recruitment of endogenous cytokines themselves to the site of injury and promote stem cell differentiation along the required lineage pathway. It is theorized that ASCs could provide antioxidants, free radical scavengers, and chaperone/heat shock proteins at an ischemic site. Toxic substances released into the local cellular environment as a direct result of the injury would be removed, thus promoting cell recovery and survival. $(39,40)$ Thus, adipose derived stem cells appear to play a significant, yet not clearly defined role in such diverse processes as skin cancer prevention, wound healing, and anesthetic enhancement of aging skin. 
Dermatological aging is influenced by intrinsic and external factors. Structural changes are a result of changes and alterations in biological molecules -proteins, glycosaminoglycan, and lipids.(41) (42) With aging, the epidermis thins. This is caused by reduction in vascularity and hydration. The thickness of the epidermis is reduced approximately $6.4 \%$ each decade with an associated decrease in the number of mast cells and fibroblasts. $(41,43,44)$ This reduction in total fibroblasts results in reduced production of collagen, elastin, glycosaminoglycans, and hyaluronic acid which leads to thinning of the dermis.(45)

Various growth factors and cytokines influenced by stem cells have an impact on the aging process. Recent studies have shown interleukins and interleukin receptors in the skin to play an important role in the regulation of the inflammatory stage of wound healing and regeneration. $(46)(47,48)$ Additional studies have shown low doses of interleukins to have an anti-aging effect. $(49,50)$ Insulin Growth Factor (IGF-1) and its binding proteins have also been shown to have an impact on aging. The ratio between Insulin Growth Factor I and Insulin Growth Factor Binding Protein 3 has been associated with facial aging and skin wrinkling by means of its influence on collagen biosynthesis.(51) In addition, dermal adipocytes have been shown to secrete adipo-cytokines such as adiponectin and leptin, which results in increased production of hyaluronic acid and collagen by human dermal fibroblasts - promoting wound healing in the skin. $(52,53)$

Some clinicians have simply injected stem cells into the skin as a therapeutic modality to promote wound healing, tissue restoration, and skin rejuvenation. However, work by Zhu et al suggests that adipose-derived stem cells injected into the soft tissue or into a defect will not alone produce soft-tissue fill. $(54,55)$ They advocate using a tissue-engineering approach, combining 
cells stimulated with certain chemical compounds and placed into a matrix or scaffold to "manufacture" an implantable neoadipose construct. In general, fillers currently on the market have not been successful in supporting an engineered tissue replacement therapy for defect repair or tissue restoration. Identifying the appropriate filler in combination with stem cells could provide an optimized microenvironment in which to create an engineered tissue that can be used as a semi-permanent filler material.

Mosely et al have noted that biomaterials can serve as a scaffold support or matrix for infiltrating cells in the wound healing process. These biomaterials have been combined with adipocyte precursors or dermal fibroblasts to produce engineered constructs for volume augmentation. The limiting factor in this process appears to be the rapidity and extent of neovascularization of the construct. It may take as long as five days for blood vessels from adjacent tissue to infiltrate into the construct and provide appropriate vascularization. This time delay can result in tissue necrosis and cell death.(56)

Investigators have studied multiple potential scaffolds combined with cells to evaluate their utility for soft-tissue treatment. Altman et al reported that magnetic resonance imaging studies revealed a consistent and stable volume fill by adipose tissue derived stem cells and non-animal stabilized hyaluronic acid at three weeks. Adipose tissue derived stem cells actively incorporated into the hyaluronic acid fill and showed an organized fibrovascular network at three weeks. They concluded that the combination of adipose tissue derived stem cells and non- 
animal stabilized hyaluronic acid shows promise as a vehicle with which to achieve lasting volume fill in reconstructive surgical soft tissue augmentation.(57)

In another study, Stillaert et all compared the hyaluronic acid sponge, HYAFF 11, with collagen sponges augmented with adipose precursor cells. HYAFF 11 was noted to be superior to collagen in supporting the differentiation and expansion of adipose precursor cells.(58)

Chung et al have reported on using hyaluronic acid (HA) - immobilized porous biodegradable microspheres for producing injectable mesenchymal stem cell aggregates for adipose tissue regeneration. They reported that HA-immobilized microspheres significantly enhanced cell differentiation and tissue regeneration when implanted in vivo, compared to unmodified porous microspheres. Their studies showed that adipose tissue derived mesenchymal stem cell cellular aggregates prepared by using porous microspheres could be delivered in an injectable manner into the body and could have great therapeutic potential for soft tissue augmentation and reconstruction.(59)

Studies by Woo et al demonstrated that beta-glucan and porous poly-lactide-co-glycoside (PLGA) membranes containing beta-glucans enhanced the cellular proliferation of adult human dermal fibroblasts (aHDF) and adipose derived stem cells (ADSC). Their studies suggest that beta-glucan and porous PLGA membranes containing beta-glucan may be useful as a material for enhancing wound healing.(60)

Deployment of stem cells with adipocytes serving as a carrier has increased in popularity. Llull reported using autologous fat as a matrix and supplemented the transplant with adipose-derived stem cells. He noted that this resulted in long-term (over one year) soft-tissue volume restoration in a patient with soft-tissue involution on the ulnar aspect of one hand. (61) Zhu, Yoshimura and 
others have published on breast augmentation utilizing stem cell enhanced adipocyte transfer and have noted $60 \%$ increased fat survival as compared to $35 \%$ with fat only.(62) In the Yoshimura study, 40 patients had $270 \mathrm{cc}$ injected into each breast with $60-80 \%$ of breast fat remaining after 2 years. (1)

\section{$\underline{\text { Acquisition, Culture, and Expansion of Adipose Derived Stem Cells }}$}

Following the identification in 2006 of adipose tissue as a rich source of adult mesenchymal stem cells and subsequent realization of their regenerative potential and wound healing properties, there has been a stimulation in its use in a variety of clinical applications. (63-66) Adipose derived stem cells are typically obtained from lipo-aspirate which is harvested via tumescent abdominal liposuction techniques or by surgical resection of adipose tissue which is then diced into the smaller segments for processing.(67) The adipose tissue, harvested either via lipo-aspiration or direct excision method, undergoes further processing using either enzymatic digestion(68) (69) or via mechanical cell separation. $(65,70)$ Despite the fact that there is extensive use of adipose tissue in clinical applications, there is no single standard protocol available for isolation and preparation of adipose tissue.(12) However, most isolation protocols consist of four basic steps: (1) washing lipo-aspirate; (2) collagenase enzyme processing; (3) centrifugation; and (4) removal of red blood cells . This process results in the production of a small pellet which is a heterogenous collection of cells, approximately $5 \%$ of which are stem 
cells. Based on laboratory experience, a volume of $500 \mathrm{cc}$ of lipo-aspirate will provide nearly 1 x $10^{9}$ adipose drive stem cells. This pellet is termed the "stromal vascular fraction" (SVF). Plating out the pellet produces adipose derived mesenchymal stem cells.

Isolation of adipose derived stem cells is an extremely complex process which involves specialized equipment, specialized reagents , and requires compliance with GMP/GCP practice guidelines. The following are examples of procedures for isolation and processing of adipose derived stem cells via stromal vascular fraction (SVF) (1)

The process typically can take over eight hours. However, Francis et al have reported on a technique for isolating viable populations of mesenchymal stem cells from lipo-aspirate fractions within thirty minutes. Reducing acquisition time of adipose derived stem cells can have a significant positive impact on their use in tissue engineering and regenerative medicine.

A syringe filled with adipose tissue harvested by lipo-aspirate technique or by direct excision would be placed in a sterile blood baguette and washed three times with sterile Dulbecco's Phosphate Buffered saline (DPB) to eliminate erythrocytes. The adipose tissue is then transferred to $60 \mathrm{ml}$ sterile centrifuge containers followed by addition of a collagenase enzyme to disrupt the fibrous tissue ( $0.3 \mathrm{mg} / \mathrm{ml}$ Liberase Blendzyme 1 using a 1:1 volume ratio).

A shaker bath at $37^{0} \mathrm{C}$. could be used for thirty minutes until a milky solution is produced or centrifuge containers could be sealed and placed in the water bath for one hour, then centrifuged 
for seven minutes at $300 \mathrm{rcf}$. During centrifugation, the stromal cells form a pellet at the bottom of the container while the adipocyte layer and debris will remain suspended.

The top layer is removed. The next layer is a collagenase solution. The "pellet" is at the bottom. The pellet is a heterogenous collection of cells, approximately $5 \%$ of which are stem cells. The pellet is also termed the "stromal vascular fraction" (SVF). Plating out the pellet produces mesenchymal stem cells.

Protocols for isolation of ASCs from adipose tissue using enzymatic digestion have been broadly applied by many researchers. In an alternative isolation technique, liposuction aspirate or finely minced adipose tissue is washed extensively with sterile phosphate buffered saline to remove blood cells, saline, and local anesthetics. Extracellular matrix is digested with $0.075 \%$ collagenase at $37^{\circ} \mathrm{C}$. for 30 minutes to release the cellular fraction. Collagenase is inactivated with an equal volume of Dulbecco's modified Eagle medium (DMEM) containing 10\% fetal bovine serum (FBS). The infranatant is centrifuged at $250 \mathrm{rcf}$ for 10 minutes to obtain a highdensity cell pellet. The pellet is resuspended in DMEM and 10\% FBS and plated in 100-mm tissue culture dishes at a density of $1 \times 10^{6}$ cells per plate. These cells are maintained in control medium (DMEM supplemented with 10\% FBS and $1 \%$ antibiotic / antimycotic ) at $37^{\circ} \mathrm{C}$. and $5 \% \mathrm{CO}^{2}$. Attached cells exhibit a fibroblast-like appearance and the potential to differentiate into adipogenic, osteogenic, chondrogenic, myogenic, and neurogenic lineages under the appropriate culture conditions. (13)

ASCs cultures under standard conditions exhibit an average population doubling time of sixty hours. The age of the donor, the type of adipose tissue (white or brown adipose tissue), the type 
of surgical procedure for preparing the specimen, culturing conditions, plating density, and media formulations all can impact the rate of tissue growth.

$\underline{\text { Stromal Vascular Fraction (SVF) }}$

Stromal vascular fraction (SVF) contains not only adipose derived stem cells (ADSCs), but also a mixed composition of cells which includes pre-adipocytes, adipocytes, macrophages, endothelial progenitor cells and growth factors. $(10,72)$ SVF has been shown to be a rich source of growth factors such as PDGF-BB, VEGF, IGF-1, and bFGF. (73)

Because of significant differences in protocols for harvesting, processing, and techniques for deployment of cells (injection techniques), it is extremely difficult to make comparisons of outcomes of clinical therapies.(74) A recent review comparing isolation techniques and processing protocols found no significant differences and therapeutic benefits dependent on pre-operative site preparation, adipose tissue harvesting techniques, centrifugation speed, or cannula size for harvesting. (75) However, additional studies and reviews are needed to substantiate these conclusions.

\section{$\underline{\text { Culturing of Adipose Derived Stem Cells }}$}

Adipose derived stem cells can be expanded via culturing techniques. This can result in a homogenous adipose derived stem cell population that expresses surface markers similar to 
bone-marrow mesenchymal stem cells-CD29, CV44, CD73, CD90, and CD105 while being negative for hematopoietic lineage markers CD 31, CD34 and CD45. (2) Multiple studies have been conducted regarding secretory properties, cell surface expression markers, multipotent potential, and immunomodulatory properties of adipose drive stem cells and bone marrow derived mesenchymal stem cells. These studies have concluded that secretory properties are similar for both adipose derived stem cells and bone marrow derived mesenchymal stem cells. (21) $(31,76-78)$

Various clinical studies have demonstrated that adipose derived stem cells accelerate wound closure, reduce scarring, promote collagen synthesis, promote angiogenesis, and improve wound tensile strength. (79) Adipose derived stem cells maintained in PRP-containing media have been shown to have a stimulatory effect on the proliferation and migration of dermal fibroblasts and keratinocytes. $(64,80,81)$ This cellular influence of adipose derived stem cells is felt to be a result of a double paracrine loop which exemplifies the intricate relationships between adipose derived stem cells in the various cellular components of the dermis and epidermis the are involved in tissue homeostasis. $(21,82)(11,27)$

While studies have shown a therapeutic effect from the use of adipose drive stem cell transplants or condition media, there is no reliable information regarding the impact donor age has regarding adipose drive stem cell regenerative or wound healing potential. Conflicting data is available concerning the effects of donor age on adipose drive stem cell function. $(31,83,84)$ However, Kato at all recently reported data which showed that, while the treatment with adult bone marrow derived mesenchymal stem cells or adipose derived stem cells in cutaneous wounds facilitated wound healing and regeneration, both of these therapies were negatively impacted by advanced stem cell donor age.(33) 
It is important to note that prolonged ex vivo culturing of adipose drive stem cells can result in significant and measurable changes due to the process of replicative senescence. $(31,83,85)$ This is manifested by loss of control of chromatin organization and activates a persistent DNA damage response which causes robust changes in transcriptional activity. $(86,87)$ These changes result in both reduction of differentiation potential of adipose derived stem cells and changes in their secretory profile which impacts paracrine function and immunomodulation. (88, 89) Gaur et al theorized that the role of senescence in aging of the adult stem cells is tightly linked to tissue maintenance and homeostasis and often viewed as an irreversible barrier to immobilization and tumorigenesis under the assumption that cellular senescence evolved to suppress tumorigenesis. $(12,88,89)$

\section{Clinical Studies Regarding Adipose Derived Stem Cells and Associated Growth Factors} and Cytokine and Current Therapeutic Applications

In recent years, a multitude of studies have demonstrated that mesenchymal stem cells have antiaging effects. Song et al ( Cytotherapy 2011) investigated the effects of ASCs on human dermal fibroblasts that were damaged through photo-aging due to UVB irradiation. Photo-damaged human fibroblasts showed greater proliferation rates in the presence of ASCs and their secreted growth factors and cytokines.(90) Metalloproteinase (MMP-1) is a known initiator of photodamage in the skin and is typically increased in fibroblasts after UV irradiation. P16 is a 
gene that controls the cell cycle and acts as a marker of cellular senescence or aging. ASCs reversed damage in photo-aged fibroblasts. ASCs reduced the number of apoptotic cells and shifted the cell cycles from necrosis to late to early apoptosis. Song's study concluded that ASCs mediate their anti-aging effects through a paracrine function on fibroblasts and can reverse damage in photo-aged fibroblasts at both the cell cycle and genetic levels.

Park et al previously demonstrated that ASCs stimulate collagen synthesis and migration of fibroblasts during wound healing. In this study they verified the mechanisms of action and effects of ASCs on skin aging.(91) Secretory factors of ASCs were investigated, and many growth factors were identified. ASC therapy caused increased dermal thickening and collagen production. In a case study, ASCs were injected intradermally (2 successive injections at 2-week internals). After 2 months improved skin texture and increased dermal thickness were documented. Park concluded that ASCs produce useful growth factors, increase collagen production and reverse skin aging.

Anti-aging of the skin is mediated by a combination of the effects of time (intrinsic aging) and environmental factors (extrinsic aging) on cellular and extracellular infrastructure These are two independent, clinically and biologically distinct, processes that affect the skin structure and function simultaneously. Growing evidence now suggests that the two aging processes have converging biochemical and molecular pathways that lead to photoaging of skin. The common mechanisms of the two aging processes may provide several unique opportunities to develop anti-aging therapies. Recent advances in understanding the role of endogenous growth factors in the aging process provide one such opportunity to develop topical anti-aging products. (92) The use of growth factors and cytokines for skin rejuvenation and reversal of photoaging is emerging as a novel anti-aging treatment. Soe and Kim showed that radio frequency created, 
microporated skin, actually created micro-channels for the topical application of growth factors.(93) One month after 3 treatment session, histological studies demonstrated increase in both dermal thickness and dermal collagen. Waible has recently reported similar finds and favorable results modifying cutaneous scaring by use lasers to recreate micro-channels to facilitate cutaneous absorption of topically applied stem cells and stem cell derived growth factors.(94-98)

Park et al reported compelling results in a large scale study for adipose derived stem cell protein extract applied transdermally. Park ( Korean J Dermatol- 2009) Providing growth factors and cytokines to cells responsible for extracellular matrix production, appeared to stimulate rejuvenation of aging skin.(99)

Brohem et al , compared fibroblasts with mesenchymal stem cells derived from bone marrow, skin, and adipose tissue to assess the differentiation potential of fibroblasts.(100) Their studies showed that fibroblasts expressed the same cell immunophenotypic markers as stem cells and were able to differentiate into the three cell lineages-adipocytes, osteocytes, and chondrocytes. Fabi and Sundaram noted growth factors and cytokines control skin growth, proliferation and differentiation by means of inter and intracellular signaling pathways. (101) They noted striking parallels between the pathways involved in skin wound healing and photo aging of skin. They noted that topical application of growth factors and injection of growth factors contained in an autologous platelet rich plasma had a positive effect on skin regeneration and rejuvenation. They noted that growth factors associated with stem cell proteins secreted by human dermal fibroblasts under hypoxic stress accelerated skin healing after laser resurfacing. They also noted that platelet-rich fibrin matrix (PRFM) facilitated skin rejuvenation. 
Lee et al reported on efficacy of micro-needling plus human stem cell condition medium for skin rejuvenation and a randomized, control, blinded, split face study in twenty-five women. Human embryonic stem cell condition medium was applied topically with enhanced dermal presentation achieved by using a $0.25 \mathrm{~mm}$ micro-needle roller.(102) Treatment sessions were repeated at two-week intervals. Improvement was noted with both pigmentation and wrinkles. Their conclusion was that secretory factors of endothelial precursor cells differentiated from human embryonic stem cells improved the signs of skin aging. Sasaki has recently reported similar findings with micro-needling. $(103,104)$

Hussain et al reported on ultrastructural changes after the use of human growth factors and cytokines skin cream as a treatment for skin rejuvenation.(105) They noted clinical, histologic, and ultrastructural changes observed after six months of application of a topical skin cream containing human growth factors and cytokines applied twice daily for six months. Clinical appearance and periorbital wrinkles improve by $33 \%$ and perioral wrinkling by $25 \%$. Histologic evaluation indicated moderate changes in epidermal thickness as well as increased fibroblast density in the superficial dermis. Electron microscopy showed ultrastructural changes consistent with new collagen formation. Their study collaborates previous studies by other researchers showing that topical application of growth factors and cytokines is beneficial in reducing signs of facial skin aging

Sundaram et al showed topically applied physiologically balance growth factors, in spite of large molecular weight, showed evidence suggesting that a small fraction of topical applied growth factors secreted by human fibroblasts grown in conditions resembling the physiological condition of the dermis and in high concentrations and in a stable formula penetrates into the deeper dermis and exhibits a physiological effect. (106) Clinical studies showed that topical 
application of product in high concentrations of physiologically balance mixture growth factors appears to reduce signs of skin aging.

Several cosmeceutical products containing either a single human growth factor or a combination of multiple human growth factors and cytokines are currently being marketed for skin rejuvenation. Clinical results for some of these products show that human growth factors, when applied topically, appear to provide beneficial effects in reducing the signs of facial aging. Fitzpatrick has reported on a proprietary mixture of growth factors and cytokines secreted by cultured neonatal human dermal fibroblasts. $(92,107)$ Patients were treated twice daily for 60 days. Results showed a $12 \%$ reduction in periorbital wrinkling after sixty days. Histologic studies showed 37\% increase in Grenz-zone collagen and a 30\% increase in dermal thickness. Hydrophilic molecules larger than 500 Da molecular weight have very little penetration through stratum corneum. Growth factors and cytokines are large hydrophilic molecules, greater than 15,000 Da molecular weight and are very unlikely to penetrate through the epidermis in amounts able to produce pharmacologic effects. Despite this fact, results of clinical studies by Fitzpatrick and others show that topical application of these macro molecules may produce clinical benefits. The primary mechanism by which the growth factors and cytokines can potentially exert their effect on the dermal matrix, is by penetration through hair follicles, sweat glands, or compromised skin - followed by interaction with cells in the dermis, such as keratinocytes, to produce signaling cytokines that affect cells (such as fibroblasts) that are deeper in the dermis. Skin may contain small imperfections resulting from dryness, scratching, or use of products containing irritating chemicals that may allow small amounts of these macro molecules to penetrate into the viable portions of the epidermis. Addition of lipophilic penetration enhancers 
or barrier-alternating peptides, may also increase penetration of these proteins through intact skin. Recent studies have shown that vaccines can exert immunologic response when applied topically. This probably results from penetration of a very small amount of protein through intact skin. Similar extent of penetration may also be sufficient for topically applied growth factors to produce an effect on epidermal cells. Epidermal-dermal communications appear to mediate the effects of topically applied growth factors and cytokines. Evidence strongly suggests the presence of a double paracrine loop where keratinocytes stimulate fibroblasts to synthesize growth factors - that in turn stimulate keratinocyte proliferation - which results in amplification of the initial effect of topical growth factors. Keratinocytes have surface receptors for many growth factors and cytokines-some of which are present in cosmetic products. Penetration of small amounts of these molecules into the viable portion of the epidermis after topical application can induce keratinocytes to produce growth factors (PDGF ,IL-1,TGF-a, \& TGF-B) which have been shown to exert a paracrine effect on proliferation and activation of dermal fibroblasts which leads to regeneration and remodeling of the dermal extracellular matrix. Although it is unclear how large proteins, such as growth factors, are able to penetrate the skin and become pharmacologically effective - early objective clinical studies and subjective observations indicate that these cosmeceutical products may potentially reduce signs of facial aging.

\section{Skin Regeneration and Wound Healing}


Pitanguy and colleagues have pointed out that restoring skin would require extensive selfrenewing stem cells. This is because of the fact that skin is characterized by an extensive selfrenewal process. They noted that progenitor cells represented in a keratinocyte culture would be capable of generating epidermal grafts.(108) The basal layer contains two types of proliferative keratinocytes: stem cells, which have unlimited self -renewal capacity, and transit amplifying cells, "daughters" of stem cells that will terminally differentiate after a few rounds of division. Cells for a skin substitute can be derived from local, systemic, and progenitor cell populations. Fibroblasts, keratinocytes, melanocytes, adipocytes, and hair follicles cells can be sourced locally and could be used for skin tissue engineering. Systemic cells are populations of cells that reside in the blood or bone marrow (such as fibrocytes) and are known to play an important role in skin wound healing. Progenitor cells are located in stem cell niches such as the hair follicle and also reside in the bone marrow.(109)

Garcia-Olmo et al reported on using adipose derived stem cells to treat non-healing fistula tracts in patients with Crohn's Disease. Following liposuction, stem cells were isolated and expanded in culture. These adipose derived stem cells were then deployed into the fistula tracts of patients with Crohn's disease. A 75\% closure rate was noted.[47] Garcia-Olmo then came back and used the pellet (the stromal vascular fraction) that was obtained at the time of surgery. When this was injected in the fistulous tract, they obtained a $25 \%$ fistula closure rate.[47] Thus, in this study, the cultured (expanded) mesenchymal stem cells were three times as effective in promoting wound healing in contaminated wounds as were the stromal vascular fractions. They concluded that cultured or manipulated stem cells secrete more growth factors or more specific cytokines to positively influence wound healing.(110) 
Autologous adipose derived stem cells have been used for the regenerative treatment of traumatic calvarial bone defects using autologous cancellous iliac bone in combination with autologous stem cells and fibrin glue. Postoperative computed tomography studies have demonstrated new bone formation with good clinical results in a limited number of cases.(111)

Stem Cell Augmentation of Adipose Tissue Grafts - Cell Assisted Lipo-transfer (CAL)

Soft tissue defects represent a reconstructive challenge. Rubin and Marra reported in 2011 that over 5.6 million procedures performed in the United States regarding this problem.(112) While the majority of cases arise from tumor extraction and the sequelae of adjunctive radiation therapy, defects of soft tissue occur from congenital abnormalities, following trauma, and are being addressed with volumization procedures for aesthetic concerns.

In cell assisted lipoma transfer (CAL), adipose derived stem cells are harvested from lipoaspirate and are used to supplement fat grafts to enhance reconstruction of facial asymmetries, post cancer radiation effects, traumatic wounds, and aesthetic concerns.(113) 
Yoshimura 2006 - noted that aspirated fat was relatively stem cells-deficient and the mechanical disruption of the adipose tissue during liposuction was thought to contribute to this loss of stem cells. (114) Yoshimura in 2008 noted improved graft retention with the supplementation of fat cells with additional adipose stem cells.(111, 115) Animal studies by Matsumoto in 2006 with subcutaneous implantation of human CAL ( cell assisted lipo transfer ) fat grafts into immunodeficiency mice demonstrated $35 \%$ increased volume retention when compared to conventional lipo transfer. (114) Tanikawa in 2013 conducted a randomized study on patients with cranial facial microsomia.(116) CAL ( cell assisted lipo transfer) was found to enhance fat volume retention compared to supplemental fat grafts. CT scans six months following grafting revealed $80 \%$ survival among patients with CAL fat grafts compared to $54 \%$ for controls, suggesting this to be an effective treatment modality for facial recontouring. Showing similar clinical support for this technique, Kolle in 2013 performed a blinded, placebo controlled trial where $30 \mathrm{cc}$ fat grafts with and without the addition of 20 million expanded ASCs per ml of fat were injected into the upper arm.(117) After 4 months, CAL fat grafts exhibited a 64.6\% increased volume. Subsequent clinical and preclinical trials by Garza (2014), Tanikawa (2013), Yoshimura (2008) and others have confirmed enhanced fat graft retention when enriched with ASCs.(116, 118, 119)

Ischemia is inherent in the process of grafting tissue. Suga in 2010 showed that ASCs appeared to be relatively resistant to hypoxic conditions and contribute to adipose tissue regeneration.(120) There is a notion that ASCs may undergo adipogenic differentiation and assist in regeneration of fat. (121) However, more recent studies, by Dong in 2015 and Garza in 2014, have suggested only transient retention of supplemental ASCs within fat grafts, and that the regions of necrosis are ultimately replaced by recipient site-derived adipocytes.(118, 119, 
$122,123)$ Both of these observations argue against the substantial contribution of ASCs to mature adipocyte tissue. Alternatively, adipose tissue is known to be rich in microvasculature and ASCs which reside around capillaries and vessels have been shown to be capable of in- vitro differentiation into the vascular endothelial cells.(124)

Matsumoto (2006) performed studies using labeled ASCs implanted with fat and showed that they subsequently stained positive for von Willebrand factor, suggesting their ability to differentiate into vascular endothelial cells and contribute to vasculogenesis in the acute phase following transplantation.(114) However, recent studies by Garza ( 2014) and Dong ( 2015) argue against a direct role of ASCs in early revascularization.(118) Nevertheless, ASCs likely exhibit a paracrine effect and have been shown to release androgenic growth factors. Zhu (2010) reported high levels of expression in ASCs of multiple pro-androgenic growth factors and noted increased capillary density within fat grafts supplemented with ASCs.(54) Garza (2014) in studies retrieved supplemental ASCs following fat grafting and noted significant up regulation of angiogenic gene expression.(118) All of these studies support a paracrine role for ASCs, promoting early revascularization of ischemic fat grafts to reduce adipocyte apoptosis and enhance long-term retention.

The critical question is how many cells are necessary to affect a meaningful (positive) change in fat graft retention. Historically, a majority of studies report employing a 1:1 approach - using $1 / 2$ of the harvested specimen for the actual adipose tissue graft and processing the other $1 / 2$ to obtain the material to serve as "supplement" for the graft. $(115,116,125)$

Paik ( 2015) reported performing titration studies regarding the number of ASCs added to autologous human fat and found that 1x105 supplemental cells per $200 \mathrm{ml}$ fat graft produced the greatest improvement in volume retention and vascularity.(126) Interestingly, significantly 
greater numbers of supplemental ASCs resulted in decreased fat graft retention-thought to be secondary to cell-cell competition between ASCs and fat graft adipocytes for the scarce resources in the hypoxic environment.

\section{Current Trends for Clinical Research and Questions that Remain to be Answered}

There is functional heterogeneity among ASCs. Whether these differences in ASC behavior are due to the actions of different ASC subpopulations or the effects of the tissue micro-environment on cell activity remains unknown. ASCs are heterogeneous with subpopulations of both proangiogenic and pro-adipogenic ASCs. In addition, Chung (2013) and Levi (2011) have pointed out that there may also be pro-osteogenic fractions. $(127,128)(129-132)$ Thus, differences in the physical microenvironment of ASCs may account for the lack of adipogenic signaling observed in supplemental ASCs in CAL. These cells are simply mixed in solution with lipo-aspirate. Ongoing research by Karam, Sivan, Zhang and others continues to investigate the use of artificial niches to direct differentiation of ASCs into keratinocytes, cardio- myocytes, osteoblasts, and other cell types.(133-136)

There are four key questions which future research must answer in order for adipose derived stem cell to become uniformly accepted treatment modalities:

\section{What subpopulations of ASCs exist?}


Adipose derived stem cells prepared from human liposuction aspirate from different studies exhibit differences in purity and molecular phenotype. Many studies show that cell preparations likely contain heterogenous populations of cells, which makes it uncertain whether the adipose derived stem cells themselves are actually responsible for the observed effects.

\section{What are the parameters that define the ASC niche?}

\section{What potential pro-and anti-tumorigenic properties of ASCs can best be titrated to maximize the potential of using ASCs in the setting of reconstructive and aesthetic surgery?}

Immunologic and angiogenic properties of adipose derived stem cells raises questions of the relationship of the cells with promoting cancer. There are several contrary studies which been published, some reports demonstrating that adipose derived stem cells could promote tumor growth. Conversely, other studies support that adipose derived stem cells can have a tumor suppressive affect.

In 2005 a priority report was published in the Journal Cancer Research from scientists in Spain and United Kingdom as the first report of spontaneous malignant transformation of human adult stem cells, supporting the hypothesis of cancer stem cell origin. They noted that while there were clinical trials that reported the safety of human adult stem cells, showing them to be highly resistant to malignant transformation, there were clear similarities between stem cells and cancer 
stem cell genetic makeup. They noted that although cells could be managed safely during the standard ex vivo expansion of 6-8 weeks, human mesenchymal stem cells could undergo spontaneous malignant transformation following long-term in vitro culture of 4-5 months. This report obviously garnered significant attention, with the result that others were unable to duplicate the reported findings. The authors and Journal subsequently retracted the paper in 2010.(137)

Breast cancer - The Journal Stem Cell International (2015) reported on a review of breast cancer and stem cells. Their conclusion was the majority of experimental studies tend to support the propensity of mesenchymal stem cells and adipose derived stem cells in promoting growth and progression and metastatic spread of residual or de novo breast cancer after resection. In contrast, however, only a few clinical case series and trials actually reflected this. Overall, they felt that most the studies did not support using autologous stem cell enhanced grafts, whereas they felt that whole fat grafting appeared to be safe in most circumstances.

While mesenchymal stromal cells represent a heterogenous population of multi-potent cells with beneficial properties for regenerative processes and with therapeutic benefit for patients being demonstrated in a wide range of severe pathologic conditions, mesenchymal stromal cell therapy may also be associated with adverse effects such as an increased recurrence rate for hematologic malignancies.(138)

Human mesenchymal stromal cells were shown to be non-tumorigenic. However, there have been reports of their capability to modulate tumor microenvironment, thus having an impact on the tumor behavior. There is increasing evidence that mesenchymal stromal cells might play a role in tumor pathogenesis and progression. Kucerova et al demonstrated tumor-promoting 
effect of adipose tissue derived mesenchymal stromal cells on human melanoma A375

cells.(139)

Rubio et al have reported that human ASCs can undergo malignant transformation with prolonged passaging over more than four months. Some feel that this may indicate that freshly isolated ASCs could possibly be a safer and a more practical source then cultured ASCs for clinical use. (137)

Mesenchymal stromal cells produce cytokines and can give rise to endothelial-like cells contributing to tumor vascular formation. Mesenchymal stromal cells were noted to have the capability to differentiate into carcinoma associated fibroblasts when under the influence of tumor-cell produced soluble factors. Manipulated human mesenchymal stromal cells were shown to have increased metastatic potential for breast cancer cells rather than significant tumor growth. $(140,141)$

\section{What are the ongoing concerns regarding adipose derived stem cells in the clinical setting?}

\section{$\underline{\text { Research Trends and FDA Oversight }}$}

In February 2014, the FDA Commissioner, the FDA Center for Biologics and Evaluation Research, and the Office of Cellular, Tissue and Gene Therapy published the FDA perspective on mesenchymal stromal cell (MSC) based clinical trials.(142) There are 4 basic parameters 
which the FDA feels influence the final stem cell product - fetal bovine serum; atmospheric oxygen; cryopreservation; and cell banking. In the last decade there has been a $300 \%$ increase in the number of Investigational New Drug trials (INDs) regarding mesenchymal stem cells (MSCs). The majority of these clinical trials ( 73\% in 2012 ) were with allogeneic donors. Bone morrow was the leading source for stem cells in the US - accounting for $55 \%$ of cases in 2013. This is in contrast to world wide data which shows bone morrow derived stem cells comprising less than half of all studies. Adipose tissue was the third most common stem cell source. However, it should be noted that there was a 3 fold increase in adipose tissue studies from 2011-2012. Over $80 \%$ of the trials used stem cells cultured in fetal bovine serum, with the average concentration being $10 \%$. It is important to point out that approximately $11 \%$ of the population have a bovine related allergy and there has been a move away from these products. However, they still comprise a significant majority of the current stem cell studies. There has been considerable discussion in the medical literature, advocated by Yoshumoro and others, regarding increased activity of stem cells when cultured in a hypoxic environment. However, $90 \%$ of US studies are using atmospheric oxygen. Cryopreservation is used by $80 \%$ to store and transport the final product with the product being thawed within a few hours of patient infusion. Most protocols call for post-thaw cell viability to exceed $70 \%$. Thirty-five per cent $(35 \%)$ of studies use cell banking, meaning that they bank the sample and expand the cell culture through multiple passages. Cardiovascular was the leading area for clinical stem cell trials followed by neurological and then orthopedics. While multiple routes of administration are used, over 50\% of the clinical trials call for the stem cells to be administered intravenously. Currently, 7 phenotypic cell markers are commonly used to monitor stem cells. However, the FDA is 
encouraging expanding this number, pointing out that markers can predict potential therapeutic benefits.

Gir et al conducted a review of the literature regarding the basic science evidence of ongoing clinical trials involving the use of adipose derived stem cells in regenerative medicine.(143) Only 33 clinical trial studies based on adipose derived stem cell therapy were identified. The majority of the studies were performed in Spain and in Korea with only three trials in United States. In all published cases, there were no major adverse events (AEs) reported and results regarding soft tissue augmentation and wound healing were noted to be very encouraging. The authors noted that there were no standards or protocols for adipose derived stem cell (ADSC) use and that further basic science experimental studies with standardized protocols and larger, randomized controlled trials were called for.

To provide a more contemporary assessment of current clinical studies, a review of Clinical Trials.Gov registered studies as of April 30, 2016 was conducted. Regarding adipose derived or bone marrow derived stem cells - a total of 164 studies were registered. Only 1 study was noted in the hair restoration area and 4 studies were noted pertaining to photo-aging and wound healing. A review of clinical studies dealing with hair was conducted. Eleven studies dealing in some degree with hair growth or hair stimulation were noted. Most studies were using platelet rich plasma (PRP). The others studies utilized adipose tissue-mainly adipose derived stromal vascular fraction (SVF). A review of clinical studies dealing with photo-aging was conducted. Seven studies were noted that dealt with photo-aging. One study employed bone marrow derived stem cells to be administered IV for photo-aging. One study utilized adipose derived 
stem cells plus hyaluronic acid as a dermal filler. Others photo-aging studies were mainly using platelet rich plasma (PRP) Two studies employed the use of adipose tissue derived SVF plus fat for enhanced fat graft viability.

\section{Status of FDA Oversight and Regulations - Cellular and Tissue Therapies}

Scientific and technological advances in stem cell biology and tissue engineering have led to the increased use of human cells and tissues for the treatment of various diseases, injuries, and aesthetic concerns. The regulatory environment for cell and tissue therapy products is rapidly evolving, with various drug regulatory agencies in many countries implementing regulatory controls in the last several years. In the United States that responsibility is under the auspices of the Food and Drug Administration (FDA) and more specifically, the Center for Biologics Evaluation and Research (CBER). (144, 145)

In the United States stem cells are considered source material and fall under FDA Human Cells, Tissues, and Cellular and Tissue - Based Products (HCT/Ps) regulation for transplantable tissues and are regulated by the FDA Center for Biologics and Evaluation Research, and the Office of Cellular, Tissue and Gene Therapy. In general, the FDA has five major concerns relating to this area: (1) transmission of communicable disease, (2) processing control to prevent contamination 
and preserve product integrity and function, (3) clinical safety and efficacy, (4) promotional claims and labeling, and (5) how best to monitor and educate industry.

Human cells, tissue, and cellular and tissue related products (HCT/Ps) are under the jurisdiction of the FDA for the regulation of transplantable tissues. When human tissues serve as "source material", the cellular products fall under the auspices of the FDA (Title 21 - Food and Drugs ; Chapter I - Food and Drug Administration; Subchapter L Regulations-Section 1271.3 -human cells, tissues, and cellular in tissue-based products). Two specific sections are applicable to HCT/PS. Section 361 regulates tissues (such as adipose tissue) and notes them to be exempt from regulation as $\mathrm{HCT} / \mathrm{Ps}$ biological drugs if:

1) cells or cellular material are "minimally manipulated"

2) cells or cellular material are not combined with any other agent (except water, crystalloids, or sterilizing, preserving, or storage agents are permitted)

3) cells or cellular material are for homologous use in the same individual ("Homologous use" is defined as the repair, reconstruction, replacement or supplementation of a recipient's cells or tissues with a HCT/P that performs the same basic function or functions in the recipient as in the donor.)

4) cells or cellular material are collected and delivered at the "same surgical setting"

Section 351 applies to all other tissues, and processes are strictly regulated by the FDA. Cell culturing (expansion) would fall into this category, as would tissues that are more than minimally manipulated; tissues for uses not "homologous"; and when there are "additives" used in the 
preparation or extraction of the cells or tissues. In such cases, these "cellular products" are subject to the regulations for high risk HCT/P's which include requiring the filing of a biologics license application; requesting permission from the FDA before proceeding to FDA-supervised clinical trials; and obtaining FDA approval prior to marketing the cellular therapy to the public. For example, harvesting autologous adipose tissue, extracting the stem cells by enzymatic digestion followed by centrifugation, and injecting the cells into non-fatty tissues (such as a joint, the heart, retina, or brain) would be considered a non-homologous use of highly manipulated cellular materials. In this example, the FDA would consider the cellular materials to be biologic drugs, regulated under Section 351.

In response to the 21 st Century Cures Act passed by Congress, in November 2017 the FDA's Center for Biologics and Research (CBER) released its new guidelines for Regenerative Medicine. They included implementing a program designated as Regenerative Medicine Advanced Therapy (RMAT). This program is available for certain cell therapies, therapeutic tissue engineering products, and certain combined products and closely mirrors accelerated pathways available for investigative drugs designed to meet serious unmet medical needs. The FDA also noted that, in an effort to modernize its regulatory framework to facilitate these scientific advances, they would consider real world evidence of safety and efficacy, as opposed to strict requirement for such data to be drawn from prospective, randomized clinical trials.

At this time, the FDA also released Guidance Documents clarifying its intention to regulate manipulated cellular materials as biologic drugs. They clarified that "same surgical procedure" exemption extended only to rinsing, cleansing, sizing, and shaping of cells or tissue biomaterials. 
They also defined "minimal manipulation" as being processes that do not alter cells' structure or biological properties and "nonhomologous use" as functions different from those ordinarily exhibited by the same cells in Vivo.

In recent years there has been a plethora of stem cell clinics that have evolved. Some the been focused on primarily aesthetic concerns, while others have proactively marketed unproven stem cell "cures" for an extraordinary array of medical conditions. For this reason, there have been calls from many sectors for the FDA to increase its regulatory authority regarding stem cell therapies.

The FDA has taken some enforcement action in the adipose stem cell space. The November 2017 Guidance Documents could also be used by State Attorneys General to stop stem cell clinics. More severe would be the impact upon the plaintiffs' bar. Plaintiff attorneys could use final guidance documents as the basis to bring claims (even class actions) against stem cell clinics operating outside of an Investigation New Drug Study. Offering stem cell therapies that do not comply with FDA regulations could also void professional liability insurance coverage. In short, the potential implications flowing from the FDA's final guidance documents could have major impacts for physicians using stem cell therapies for aesthetic purposes.

There are 4 key areas that the FDA feels must have validation for future therapeutic uses of stem cells to be permitted: (1) Safety - must have disease screening of all donors and also insure any agents used in manufacturing process have no deleterious effect. (2) Potency - must have 
validation assays to insure consistency of processes and reactive agents so know the resultant reactions are reproducible. (3) Purity - look at flow cytometry and genetic analysis - want to be sure all cells are human (culture has not become contaminated and essentially that the cells are the type of cells that you think they are). If stem cell cultures are highly expanded, karyotyping is important to be sure there are no mutations. Typically, one would perform 3 passages - any pluripotent cells would have been removed in the process and you would be left with only multipotent cells (safer). (4) Efficacy - which is essentially outcome measurement.

There have been 2 main problems hampering stem cell therapy: (1) need to expand cells in fetal bovine serum and (2) purity of culture lines. Cell expansion required culturing on a fetal bovine serum medium. For an estimated $10 \%-11 \%$ of the population, this is a potential allergen. New techniques to culture and expand cells in one's own blood and also in a human platelet lysate extract eliminates this problem. Initial studies seem to indicate that human platelet lysate (HPL) cytokines may actually enhance both expansion rate for stem cells and their clinical efficacy. Regarding purity of cell cultures, it has been shown that there is functional heterogeneity among mesenchymal stromal cells (MSCs). Whether these differences in MSC behavior are due to the actions of different MSC subpopulations or the effects of the tissue micro-environment on cell activity remains unknown. MSCs are heterogeneous with subpopulations of both pro-angiogenic and pro- adipogenic MSCs. There is ongoing research investigating the use of artificial niches to direct differentiation of MSCs into keratinocytes, cardio myocytes, osteoblasts, and other cells. Future stem cell research needs to focus on answering 3 key questions: (1) What subpopulations of stem cells exist? (2) What are the parameters that define the stem cell niche? (3) What 
potential pro-and anti-tumorigenic properties of stem cells can best be titrated to maximize the benefit and potential of using stem cells in reconstructive and aesthetic surgery?

Presently, adipose derived stem cells appear to be the stem cells used most frequently in aesthetic and soft tissue reconstructive procedures. What are the ongoing concerns regarding adipose derived stem cells in the clinical setting which need to be addressed with future research efforts? (1) Adipose derived stem cells prepared from human liposuction aspirate from different studies exhibit differences in purity and molecular phenotype. Many studies show that cell preparations likely contain heterogenous populations of cells, which makes it uncertain whether the adipose derived stem cells themselves are actually responsible for the observed effects. (2) Immunologic and angiogenic properties of adipose derived stem cells raises questions regarding the relationship of the cells with promoting cancer. There are several contrary studies which been published - some reports demonstrating that adipose derived stem cells could promote tumor growth and other studies supporting that adipose derived stem cells can have a tumor suppressive affect. Answers to the question remain unknown and further studies are necessary.

\section{$\underline{\text { Future Trends }}$}

Because of the volume of research compared to other cellular therapies; the impressive clinical outcomes reported in many studies; and the fact that that it is easy to obtain with minimal morbidity; adipose tissue derived stem cells appear to be the focus of the majority of research 
efforts and clinical studies for cellular therapies in the anesthetic realm. Adipose tissue is currently recognized as an accessible and abundant source for adult stem cells which are suitable for tissue engineering and regenerative medicine applications. The importance of adipose tissue in future advanced cellular therapies is bolstered by the fact that adipose tissue can be cryopreserved with resultant viability of adipose drive stem cells obtained from the preserved tissue. Studies have shown that adipose tissue frozen at $-80^{\circ} \mathrm{C}$ exhibited a cellular viability of $87 \%$ after more than 1 year of cryopreservation. (146)

This opens the door to patients undergoing elective aesthetic procedures requesting that their adipose tissue be harvested and tissue banked, similar to the cryopreservation of infant cord blood and the banking of extracted wisdom teeth by oral surgeons for the preservation of dental derived stem cells. This is based on the premise that the discovery of induced pluripotent stem cells (iPSCs) and their potential to function in a capacity similar to that of embryonic stem cells, will unable patients who lost the opportunity to have their cord blood preserved as newborns to take advantage of this "second chance" and have tissue preserved for therapeutic and regenerative treatments that are yet to be discovered. (1)

While there have been significant advances made in the use of adipose derived stem cells in tissue engineering, there are two main obstacles which continue to hinder the progress of tissue engineering - neovascularization and matrix scaffold. Biologic structures larger than $200 \mu$ in diameter require a vascular system for nutritional support. A limited number of materials are available that can serve as scaffold which can foster tissue in growth. Innovative synthetic materials, such as poly-peptides or novel biodegradable polymers are needed that will control 
tissue topology and have surface modifications to stimulate cell attachment, differentiation and growth. $(1,109)$ The delivery of growth factors and chemical substance to guide tissue formation from stem cells encapsulated in biocompatible polymer scaffolds holds great promise for significant advances in aesthetic surgery.

Cellular therapies and tissue engineering are still in their infancy, and additional basic science and pre-clinical studies are needed before cosmetic and reconstructive surgical applications can be routinely undertaken and satisfactory levels of patient safety achieved.(3) However, significant advances continue to be made in the cellular therapies and tissue injury. Innovations on the horizon include: development of xeno-free and enzyme-free culturing and manufacturing capabilities and cellular therapies derived from specific cell niches such as skin basal cell layer, hair bulb, and body tissues. All are exciting research areas that hold great promise.

From a historical perspective, new and emerging therapies and technologies have usually been met with skepticism, even those which have later become mainstay clinical therapies. In the late 1960s, a South Carolina surgeon was widely criticized for using a gastric bypass surgical technique for weight control. Today, that same therapy is viewed as the most effective treatment for morbid obesity and is the recommended treatment for those with a BMI of 40 or above. Using fecal implants to treat $C$. Diff certainly was met with significant skepticism and was considered "over the top" when first proposed. Today, fecal microbiota transplant is considered a main line treatment, and pharmaceutical companies have invested millions of dollars in the development of fecal bacteriotherapy. It is important that as physician scientists, we keep an open mind, maintain an evidenced based perspective, and hold the safety of our patients as paramount importance. 
1. Beeson W, Woods E, Agha R. Tissue engineering, regenerative medicine, and rejuvenation in 2010: the role of adipose-derived stem cells. Facial plastic surgery : FPS. 2011;27(4):378-87.

2. Zuk PA, Zhu M, Ashjian P, De Ugarte DA, Huang Jl, Mizuno $\mathrm{H}$, et al. Human adipose tissue is a source of multipotent stem cells. Molecular biology of the cell. 2002;13(12):4279-95.

3. Zuk PA. The adipose-derived stem cell: looking back and looking ahead. Molecular biology of the cell. 2010;21(11):1783-7.

4. Mizuno $\mathrm{H}$. Adipose-derived stem cells for tissue repair and regeneration: ten years of research and a literature review. Journal of Nippon Medical School = Nippon Ika Daigaku zasshi. 2009;76(2):56-66.

5. Pittenger MF, Mackay AM, Beck SC, Jaiswal RK, Douglas R, Mosca JD, et al. Multilineage potential of adult human mesenchymal stem cells. Science (New York, NY). 1999;284(5411):143-7.

6. Takahashi K, Tanabe K, Ohnuki M, Narita M, Ichisaka T, Tomoda K, et al. Induction of Pluripotent Stem Cells from Adult Human Fibroblasts by Defined Factors. Cell.131(5):861-72.

7. Camara DA, Mambelli LI, Porcacchia AS, Kerkis I. Advances and Challenges on Cancer Cells Reprogramming Using Induced Pluripotent Stem Cells Technologies. J Cancer. 2016;7(15):2296-303. 
8. <derm stem cells 119 18.pdf>.

9. Gratama J, Kvalheim G, Orfao A. Standardization of cell analysis methods in clinical cellular therapy programs: A challenge for ISCT. Cytotherapy. 2006;8(6):528-9.

10. Bourin P, Bunnell BA, Casteilla L, Dominici M, Katz AJ, March KL, et al. Stromal cells from the adipose tissue-derived stromal vascular fraction and culture expanded adipose tissue-derived stromal/stem cells: a joint statement of the International Federation for Adipose Therapeutics and Science (IFATS) and the International Society for Cellular Therapy (ISCT). Cytotherapy. 2013;15(6):641-8. 11. Abbott S, Mackay G, Durdy M, Solomon S, Zylberberg C. Twenty years of the International Society for Cellular Therapies: the past, present and future of cellular therapy clinical development. Cytotherapy. 2014;16(4 Suppl):S112-9.

12. Gaur M, Dobke M, Lunyak VV. Mesenchymal Stem Cells from Adipose Tissue in Clinical Applications for Dermatological Indications and Skin Aging. International journal of molecular sciences. 2017;18(1).

13. Izadpanah R, Trygg C, Patel B, Kriedt C, Dufour J, Gimble JM, et al. Biologic properties of mesenchymal stem cells derived from bone marrow and adipose tissue. Journal of cellular biochemistry. 2006;99(5):1285-97.

14. Watson D, Keller GS, Lacombe V, Fodor PB, Rawnsley J, Lask GP. Autologous fibroblasts for treatment of facial rhytids and dermal depressions. A pilot study. Archives of facial plastic surgery. 1999;1(3):165-70.

15. Mizuno H, Itoi $Y$, Kawahara S, Ogawa R, Akaishi S, Hyakusoku H. In vivo adipose tissue regeneration by adipose-derived stromal cells isolated from GFP transgenic mice. Cells, tissues, organs. 2008;187(3):177-85.

16. Zuk PA, Zhu M, Mizuno H, Huang J, Futrell JW, Katz AJ, et al. Multilineage cells from human adipose tissue: implications for cell-based therapies. Tissue engineering. 2001;7(2):211-28.

17. Tobita M, Uysal AC, Ogawa R, Hyakusoku H, Mizuno H. Periodontal tissue regeneration with adipose-derived stem cells. Tissue engineering Part A. 2008;14(6):945-53.

18. Gimble JM. Adipose tissue-derived therapeutics. Expert opinion on biological therapy. 2003;3(5):705-13.

19. Zouboulis CC, Makrantonaki E. Clinical aspects and molecular diagnostics of skin aging. Clinics in dermatology. 2011;29(1):3-14.

20. Zouboulis CC, Boschnakow A. Chronological ageing and photoageing of the human sebaceous gland. Clinical and experimental dermatology. 2001;26(7):600-7.

21. Kilroy GE, Foster SJ, Wu X, Ruiz J, Sherwood S, Heifetz A, et al. Cytokine profile of human adipose-derived stem cells: expression of angiogenic, hematopoietic, and pro-inflammatory factors. Journal of cellular physiology. 2007;212(3):702-9.

22. Cappuzzello C, Doni A, Dander E, Pasqualini F, Nebuloni M, Bottazzi B, et al. Mesenchymal Stromal Cell-Derived PTX3 Promotes Wound Healing via Fibrin Remodeling. The Journal of investigative dermatology. 2016;136(1):293-300.

23. Ozpur MA, Guneren E, Canter HI, Karaaltin MV, Ovali E, Yogun FN, et al. Generation of Skin Tissue Using Adipose Tissue-Derived Stem Cells. Plastic and reconstructive surgery. 2016;137(1):134-43.

24. Barry BW. Novel mechanisms and devices to enable successful transdermal drug delivery. European journal of pharmaceutical sciences : official journal of the European Federation for Pharmaceutical Sciences. 2001;14(2):101-14.

25. Elias PM, Friend DS. The permeability barrier in mammalian epidermis. The Journal of cell biology. 1975;65(1):180-91.

26. Nemes Z, Steinert PM. Bricks and mortar of the epidermal barrier. Experimental \& molecular medicine. 1999;31(1):5-19. 
27. Foldvari M. Non-invasive administration of drugs through the skin: challenges in delivery system design. Pharmaceutical science \& technology today. 2000;3(12):417-25.

28. Bouwstra JA, Ponec M. The skin barrier in healthy and diseased state. Biochimica et biophysica acta. 2006;1758(12):2080-95.

29. Mesa KR, Rompolas P, Zito G, Myung P, Sun TY, Brown S, et al. Niche-induced cell death and epithelial phagocytosis regulate hair follicle stem cell pool. Nature. 2015;522(7554):94-7.

30. Blanpain C, Fuchs E. Epidermal homeostasis: a balancing act of stem cells in the skin. Nature reviews Molecular cell biology. 2009;10(3):207-17.

31. Niu P, Smagul A, Wang L, Sadvakas A, Sha Y, Perez LM, et al. Transcriptional profiling of interleukin-2-primed human adipose derived mesenchymal stem cells revealed dramatic changes in stem cells response imposed by replicative senescence. Oncotarget. 2015;6(20):17938-57.

32. Schmidt BA, Horsley V. Intradermal adipocytes mediate fibroblast recruitment during skin wound healing. Development (Cambridge, England). 2013;140(7):1517-27.

33. Kato J, Kamiya H, Himeno T, Shibata T, Kondo M, Okawa T, et al. Mesenchymal stem cells ameliorate impaired wound healing through enhancing keratinocyte functions in diabetic foot ulcerations on the plantar skin of rats. Journal of diabetes and its complications. 2014;28(5):588-95.

34. Kemp MG, Spandau DF, Simman R, Travers JB. Insulin-like Growth Factor 1 Receptor Signaling Is Required for Optimal ATR-CHK1 Kinase Signaling in Ultraviolet B (UVB)-irradiated Human Keratinocytes. The Journal of biological chemistry. 2017;292(4):1231-9.

35. Kemp MG, Spandau DF, Travers JB. Impact of Age and Insulin-Like Growth Factor-1 on DNA Damage Responses in UV-Irradiated Human Skin. Molecules (Basel, Switzerland). 2017;22(3).

36. Krbanjevic A, Travers JB, Spandau DF. How Wounding via Lasers Has Potential Photocarcinogenic Preventative Effects via Dermal Remodeling. Current dermatology reports. 2016;5(3):222-7.

37. Lewis DA, Travers JB, Spandau DF. A new paradigm for the role of aging in the development of skin cancer. The Journal of investigative dermatology. 2009;129(3):787-91.

38. Cao Y, Sun Z, Liao L, Meng Y, Han Q, Zhao RC. Human adipose tissue-derived stem cells differentiate into endothelial cells in vitro and improve postnatal neovascularization in vivo. Biochem Biophys Res Commun. 2005;332(2):370-9.

39. Gimble JM, Guilak F, Bunnell BA. Clinical and preclinical translation of cell-based therapies using adipose tissue-derived cells. Stem cell research \& therapy. 2010;1(2):19.

40. Gimble JM, Floyd ZE, Bunnell BA. The 4th dimension and adult stem cells: Can timing be everything? Journal of cellular biochemistry. 2009;107(4):569-78.

41. Waller JM, Maibach HI. Age and skin structure and function, a quantitative approach (I): blood flow, $\mathrm{pH}$, thickness, and ultrasound echogenicity. Skin research and technology : official journal of International Society for Bioengineering and the Skin (ISBS) [and] International Society for Digital Imaging of Skin (ISDIS) [and] International Society for Skin Imaging (ISSI). 2005;11(4):221-35.

42. Farage MA, Miller KW, Elsner $P$, Maibach HI. Functional and physiological characteristics of the aging skin. Aging clinical and experimental research. 2008;20(3):195-200.

43. Oriba HA, Bucks DA, Maibach HI. Percutaneous absorption of hydrocortisone and testosterone on the vulva and forearm: effect of the menopause and site. The British journal of dermatology. $1996 ; 134(2): 229-33$.

44. Duncan KO, Leffell DJ. Preoperative assessment of the elderly patient. Dermatologic clinics. 1997;15(4):583-93.

45. Makrantonaki E, Zouboulis CC. Molecular mechanisms of skin aging: state of the art. Annals of the New York Academy of Sciences. 2007;1119:40-50.

46. Gragnani A, Cezillo MV, da Silva ID, de Noronha SM, Correa-Noronha SA, Ferreira LM. Gene expression profile of cytokines and receptors of inflammation from cultured keratinocytes of burned patients. Burns : journal of the International Society for Burn Injuries. 2014;40(5):947-56. 
47. Adachi T, Kobayashi T, Sugihara E, Yamada T, Ikuta K, Pittaluga S, et al. Hair follicle-derived IL-7 and IL-15 mediate skin-resident memory T cell homeostasis and lymphoma. Nature medicine. 2015;21(11):1272-9.

48. Knipper JA, Willenborg S, Brinckmann J, Bloch W, Maass T, Wagener R, et al. Interleukin-4 Receptor alpha Signaling in Myeloid Cells Controls Collagen Fibril Assembly in Skin Repair. Immunity. 2015;43(4):803-16.

49. Crane JD, MacNeil LG, Lally JS, Ford RJ, Bujak AL, Brar IK, et al. Exercise-stimulated interleukin-15 is controlled by AMPK and regulates skin metabolism and aging. Aging cell. 2015;14(4):625-34.

50. Kim DW, Jeon BJ, Hwang NH, Kim MS, Park SH, Dhong ES, et al. Adipose-derived stem cells inhibit epidermal melanocytes through an interleukin-6-mediated mechanism. Plastic and reconstructive surgery. 2014;134(3):470-80.

51. Noordam R, Gunn DA, Tomlin CC, Maier AB, Griffiths T, Catt SD, et al. Serum insulin-like growth factor 1 and facial ageing: high levels associate with reduced skin wrinkling in a cross-sectional study. The British journal of dermatology. 2013;168(3):533-8.

52. Ezure T, Amano S. Adiponectin and leptin up-regulate extracellular matrix production by dermal fibroblasts. BioFactors (Oxford, England). 2007;31(3-4):229-36.

53. Tadokoro S, Ide S, Tokuyama R, Umeki H, Tatehara S, Kataoka S, et al. Leptin promotes wound healing in the skin. PloS one. 2015;10(3):e0121242.

54. Zhu M, Zhou Z, Chen Y, Schreiber R, Ransom JT, Fraser JK, et al. Supplementation of fat grafts with adipose-derived regenerative cells improves long-term graft retention. Annals of plastic surgery. 2010;64(2):222-8.

55. Zhu Y, Liu T, Song K, Jiang B, Ma X, Cui Z. Collagen-chitosan polymer as a scaffold for the proliferation of human adipose tissue-derived stem cells. Journal of materials science Materials in medicine. 2009;20(3):799-808.

56. Moseley TA, Zhu M, Hedrick MH. Adipose-derived stem and progenitor cells as fillers in plastic and reconstructive surgery. Plastic and reconstructive surgery. 2006;118(3 Suppl):121s-8s.

57. Altman AM, Abdul Khalek FJ, Seidensticker M, Pinilla S, Yan Y, Coleman M, et al. Human tissueresident stem cells combined with hyaluronic acid gel provide fibrovascular-integrated soft-tissue augmentation in a murine photoaged skin model. Plastic and reconstructive surgery. 2010;125(1):63-73. 58. Stillaert FB, Di Bartolo C, Hunt JA, Rhodes NP, Tognana E, Monstrey S, et al. Human clinical experience with adipose precursor cells seeded on hyaluronic acid-based spongy scaffolds. Biomaterials. 2008;29(29):3953-9.

59. Chung HJ, Jung JS, Park TG. Fabrication of Adipose-Derived Mesenchymal Stem Cell Aggregates using Biodegradable Porous Microspheres for Injectable Adipose Tissue Regeneration. Journal of biomaterials science Polymer edition. 2011;22(1-3):107-22.

60. Woo YI, Park BJ, Kim HL, Lee MH, Kim J, Yang Yl, et al. The biological activities of $(1,3)-(1,6)$-betad-glucan and porous electrospun PLGA membranes containing beta-glucan in human dermal fibroblasts and adipose tissue-derived stem cells. Biomedical materials (Bristol, England). 2010;5(4):044109.

61. Tholpady SS, Llull R, Ogle RC, Rubin JP, Futrell JW, Katz AJ. Adipose tissue: stem cells and beyond. Clinics in plastic surgery. 2006;33(1):55-62, vi.

62. Yoshimura K, Suga H, Eto H. Adipose-derived stem/progenitor cells: roles in adipose tissue remodeling and potential use for soft tissue augmentation. Regenerative medicine. 2009;4(2):265-73.

63. Kapur SK, Dos-Anjos Vilaboa S, Llull R, Katz AJ. Adipose tissue and stem/progenitor cells: discovery and development. Clinics in plastic surgery. 2015;42(2):155-67.

64. Hassan WU, Greiser U, Wang W. Role of adipose-derived stem cells in wound healing. Wound repair and regeneration : official publication of the Wound Healing Society [and] the European Tissue Repair Society. 2014;22(3):313-25. 
65. Conde-Green A, Kotamarti VS, Sherman LS, Keith JD, Lee ES, Granick MS, et al. Shift toward Mechanical Isolation of Adipose-derived Stromal Vascular Fraction: Review of Upcoming Techniques. Plastic and reconstructive surgery Global open. 2016;4(9):e1017.

66. Negenborn VL, Groen JW, Smit JM, Niessen FB, Mullender MG. The Use of Autologous Fat Grafting for Treatment of Scar Tissue and Scar-Related Conditions: A Systematic Review. Plastic surgical nursing : official journal of the American Society of Plastic and Reconstructive Surgical Nurses. 2016;36(3):131-43.

67. Shridharani SM, Broyles JM, Matarasso A. Liposuction devices: technology update. Medical devices (Auckland, NZ). 2014;7:241-51.

68. Peters EM, Liotiri S, Bodo E, Hagen E, Biro T, Arck PC, et al. Probing the effects of stress mediators on the human hair follicle: substance $\mathrm{P}$ holds central position. The American journal of pathology. 2007;171(6):1872-86.

69. Banyard DA, Salibian AA, Widgerow AD, Evans GR. Implications for human adipose-derived stem cells in plastic surgery. J Cell Mol Med. 2015;19(1):21-30.

70. Cleveland EC, Albano NJ, Hazen A. Roll, Spin, Wash, or Filter? Processing of Lipoaspirate for Autologous Fat Grafting: An Updated, Evidence-Based Review of the Literature. Plastic and reconstructive surgery. 2015;136(4):706-13.

71. Francis MP, Sachs PC, Elmore LW, Holt SE. Isolating adipose-derived mesenchymal stem cells from lipoaspirate blood and saline fraction. Organogenesis. 2010;6(1):11-4.

72. Hanke A, Prantl L, Wenzel C, Nerlich M, Brockhoff G, Loibl M, et al. Semi-automated extraction and characterization of Stromal Vascular Fraction using a new medical device. Clinical hemorheology and microcirculation. 2016;64(3):403-12.

73. Grasys J, Kim BS, Pallua N. Content of Soluble Factors and Characteristics of Stromal Vascular Fraction Cells in Lipoaspirates from Different Subcutaneous Adipose Tissue Depots. Aesthetic surgery journal / the American Society for Aesthetic Plastic surgery. 2016;36(7):831-41.

74. Kakagia D, Pallua N. Autologous fat grafting: in search of the optimal technique. Surgical innovation. 2014;21(3):327-36.

75. Strong AL, Cederna PS, Rubin JP, Coleman SR, Levi B. The Current State of Fat Grafting: A Review of Harvesting, Processing, and Injection Techniques. Plastic and reconstructive surgery. 2015;136(4):897912.

76. Strioga M, Viswanathan S, Darinskas A, Slaby O, Michalek J. Same or not the same? Comparison of adipose tissue-derived versus bone marrow-derived mesenchymal stem and stromal cells. Stem cells and development. 2012;21(14):2724-52.

77. Melief SM, Schrama E, Brugman MH, Tiemessen MM, Hoogduijn MJ, Fibbe WE, et al. Multipotent stromal cells induce human regulatory $T$ cells through a novel pathway involving skewing of monocytes toward anti-inflammatory macrophages. Stem cells (Dayton, Ohio). 2013;31(9):1980-91.

78. Li CY, Wu XY, Tong JB, Yang XX, Zhao JL, Zheng QF, et al. Comparative analysis of human mesenchymal stem cells from bone marrow and adipose tissue under xeno-free conditions for cell therapy. Stem cell research \& therapy. 2015;6:55.

79. Toyserkani NM, Christensen ML, Sheikh SP, Sorensen JA. Adipose-Derived Stem Cells: New Treatment for Wound Healing? Annals of plastic surgery. 2015;75(1):117-23.

80. Stessuk T, Puzzi MB, Chaim EA, Alves PC, de Paula EV, Forte A, et al. Platelet-rich plasma (PRP) and adipose-derived mesenchymal stem cells: stimulatory effects on proliferation and migration of fibroblasts and keratinocytes in vitro. Archives of dermatological research. 2016;308(7):511-20.

81. Son WC, Yun JW, Kim BH. Adipose-derived mesenchymal stem cells reduce MMP-1 expression in UV-irradiated human dermal fibroblasts: therapeutic potential in skin wrinkling. Bioscience, biotechnology, and biochemistry. 2015;79(6):919-25. 
82. Hocking AM, Gibran NS. Mesenchymal stem cells: paracrine signaling and differentiation during cutaneous wound repair. Experimental cell research. 2010;316(14):2213-9.

83. Lopez MF, Niu P, Wang L, Vogelsang M, Gaur M, Krastins B, et al. Opposing activities of oncogenic MIR17HG and tumor suppressive MIR100HG clusters and their gene targets regulate replicative senescence in human adult stem cells. NPJ aging and mechanisms of disease. 2017;3:7.

84. Tollervey JR, Lunyak VV. Adult stem cells: simply a tool for regenerative medicine or an additional piece in the puzzle of human aging? Cell cycle (Georgetown, Tex). 2011;10(24):4173-6.

85. Bhandari DR, Seo KW, Sun B, Seo MS, Kim HS, Seo YJ, et al. The simplest method for in vitro beta-cell production from human adult stem cells. Differentiation; research in biological diversity. 2011;82(3):144-52.

86. Gruber HE, Somayaji S, Riley F, Hoelscher GL, Norton HJ, Ingram J, et al. Human adipose-derived mesenchymal stem cells: serial passaging, doubling time and cell senescence. Biotechnic \& histochemistry : official publication of the Biological Stain Commission. 2012;87(4):303-11.

87. Jun HS, Dao LT, Pyun JC, Cho S. Effect of cell senescence on the impedance measurement of adipose tissue-derived stem cells. Enzyme and microbial technology. 2013;53(5):302-6.

88. von Mering C, Jensen LJ, Snel B, Hooper SD, Krupp M, Foglierini M, et al. STRING: known and predicted protein-protein associations, integrated and transferred across organisms. Nucleic acids research. 2005;33(Database issue):D433-7.

89. Jeyapalan JC, Sedivy JM. Cellular senescence and organismal aging. Mechanisms of ageing and development. 2008;129(7-8):467-74.

90. Song SY, Jung JE, Jeon YR, Tark KC, Lew DH. Determination of adipose-derived stem cell application on photo-aged fibroblasts, based on paracrine function. Cytotherapy. 2011;13(3):378-84.

91. Park BS, Jang KA, Sung JH, Park JS, Kwon YH, Kim KJ, et al. Adipose-derived stem cells and their secretory factors as a promising therapy for skin aging. Dermatologic surgery : official publication for American Society for Dermatologic Surgery [et al]. 2008;34(10):1323-6.

92. Mehta RC, Fitzpatrick RE. Endogenous growth factors as cosmeceuticals. Dermatologic therapy. 2007;20(5):350-9.

93. Kim SG, Kim EY, Kim YJ, Lee SI. The Efficacy and Safety of Ablative Fractional Resurfacing Using a 2,940-Nm Er:YAG Laser for Traumatic Scars in the Early Posttraumatic Period. Archives of plastic surgery. 2012;39(3):232-7.

94. Issler-Fisher AC, Waibel JS, Donelan MB. Laser Modulation of Hypertrophic Scars: Technique and Practice. Clinics in plastic surgery. 2017;44(4):757-66.

95. Waibel JS, Rudnick A. Laser-Assisted Delivery to Treat Facial Scars. Facial plastic surgery clinics of North America. 2017;25(1):105-17.

96. Waibel JS, Rudnick A, Shagalov DR, Nicolazzo DM. Update of Ablative Fractionated Lasers to Enhance Cutaneous Topical Drug Delivery. Advances in therapy. 2017;34(8):1840-9.

97. Waibel JS, Rudnick AC, Wulkan AJ, Holmes JD. The Diagnostic Role of Optical Coherence Tomography (OCT) in Measuring the Depth of Burn and Traumatic Scars for More Accurate Laser Dosimetry: Pilot Study. Journal of drugs in dermatology : JDD. 2016;15(11):1375-80.

98. Waibel JS, Wulkan AJ, Shumaker PR. Treatment of hypertrophic scars using laser and laser assisted corticosteroid delivery. Lasers in surgery and medicine. 2013;45(3):135-40.

99. Kim WS, Park BS, Park SH, Kim HK, Sung JH. Antiwrinkle effect of adipose-derived stem cell: activation of dermal fibroblast by secretory factors. Journal of dermatological science. 2009;53(2):96102.

100. Brohem CA, de Carvalho CM, Radoski CL, Santi FC, Baptista MC, Swinka BB, et al. Comparison between fibroblasts and mesenchymal stem cells derived from dermal and adipose tissue. International journal of cosmetic science. 2013;35(5):448-57. 
101. Fabi S, Sundaram $\mathrm{H}$. The potential of topical and injectable growth factors and cytokines for skin rejuvenation. Facial plastic surgery : FPS. 2014;30(2):157-71.

102. Lee HJ, Lee EG, Kang S, Sung JH, Chung HM, Kim DH. Efficacy of microneedling plus human stem cell conditioned medium for skin rejuvenation: a randomized, controlled, blinded split-face study. Annals of dermatology. 2014;26(5):584-91.

103. Sasaki GH. Response to Commentaries on "Micro-Needling Depth Penetration, Presence of Pigment Particles, and Fluorescein-Stained Platelets: Clinical Usage for Aesthetic Concerns". Aesthetic surgery journal / the American Society for Aesthetic Plastic surgery. 2017;37(5):Np60-np1.

104. Sasaki GH. Micro-Needling Depth Penetration, Presence of Pigment Particles, and FluoresceinStained Platelets: Clinical Usage for Aesthetic Concerns. Aesthetic surgery journal / the American Society for Aesthetic Plastic surgery. 2017;37(1):71-83.

105. Hussain M, Phelps R, Goldberg DJ. Clinical, histologic, and ultrastructural changes after use of human growth factor and cytokine skin cream for the treatment of skin rejuvenation. Journal of cosmetic and laser therapy : official publication of the European Society for Laser Dermatology. 2008;10(2):104-9.

106. Sundaram H, Mehta RC, Norine JA, Kircik L, Cook-Bolden FE, Atkin DH, et al. Topically applied physiologically balanced growth factors: a new paradigm of skin rejuvenation. Journal of drugs in dermatology : JDD. 2009;8(5 Suppl Skin Rejuenation):4-13.

107. Fitzpatrick RE, Rostan EF. Reversal of photodamage with topical growth factors: a pilot study. Journal of cosmetic and laser therapy : official publication of the European Society for Laser Dermatology. 2003;5(1):25-34.

108. Sterodimas A, De Faria J, Correa WE, Pitanguy I. Tissue engineering in plastic surgery: an up-todate review of the current literature. Annals of plastic surgery. 2009;62(1):97-103.

109. Sterodimas A, de Faria J, Nicaretta B, Papadopoulos O, Papalambros E, Illouz YG. Cell-assisted lipotransfer. Aesthetic surgery journal / the American Society for Aesthetic Plastic surgery.

2010;30(1):78-81.

110. Garcia-Olmo D, Garcia-Arranz M, Herreros D. Expanded adipose-derived stem cells for the treatment of complex perianal fistula including Crohn's disease. Expert opinion on biological therapy. 2008;8(9):1417-23.

111. Yoshimura K, Sato K, Aoi N, Kurita M, Inoue K, Suga H, et al. Cell-assisted lipotransfer for facial lipoatrophy: efficacy of clinical use of adipose-derived stem cells. Dermatologic surgery : official publication for American Society for Dermatologic Surgery [et al]. 2008;34(9):1178-85.

112. Rubin JP, Marra KG. Soft tissue reconstruction. Methods in molecular biology (Clifton, NJ). 2011;702:395-400.

113. Rubin JP, Marra KG. Commentary. Cell-assisted lipotransfer (CAL). Aesthetic surgery journal / the American Society for Aesthetic Plastic surgery. 2010;30(1):82.

114. Matsumoto D, Sato K, Gonda K, Takaki Y, Shigeura T, Sato T, et al. Cell-assisted lipotransfer: supportive use of human adipose-derived cells for soft tissue augmentation with lipoinjection. Tissue engineering. 2006;12(12):3375-82.

115. Yoshimura K, Sato K, Aoi N, Kurita M, Hirohi T, Harii K. Cell-assisted lipotransfer for cosmetic breast augmentation: supportive use of adipose-derived stem/stromal cells. Aesthetic plastic surgery. 2008;32(1):48-55; discussion 6-7.

116. Tanikawa DY, Aguena M, Bueno DF, Passos-Bueno MR, Alonso N. Fat grafts supplemented with adipose-derived stromal cells in the rehabilitation of patients with craniofacial microsomia. Plastic and reconstructive surgery. 2013;132(1):141-52.

117. Kolle SF, Fischer-Nielsen A, Mathiasen AB, Elberg JJ, Oliveri RS, Glovinski PV, et al. Enrichment of autologous fat grafts with ex-vivo expanded adipose tissue-derived stem cells for graft survival: a randomised placebo-controlled trial. Lancet (London, England). 2013;382(9898):1113-20. 
118. Garza RM, Paik KJ, Chung MT, Duscher D, Gurtner GC, Longaker MT, et al. Studies in fat grafting: Part III. Fat grafting irradiated tissue--improved skin quality and decreased fat graft retention. Plastic and reconstructive surgery. 2014;134(2):249-57.

119. Ansorge H, Garza JR, McCormack MC, Leamy P, Roesch S, Barere A, et al. Autologous fat processing via the Revolve system: quality and quantity of fat retention evaluated in an animal model. Aesthetic surgery journal / the American Society for Aesthetic Plastic surgery. 2014;34(3):438-47.

120. Suga $\mathrm{H}$, Eto $\mathrm{H}$, Aoi N, Kato H, Araki J, Doi K, et al. Adipose tissue remodeling under ischemia: death of adipocytes and activation of stem/progenitor cells. Plastic and reconstructive surgery. 2010;126(6):1911-23.

121. Kato H, Araki J, Doi K, Kuno S, Kinoshita K, Mineda K, et al. Normobaric hyperoxygenation enhances initial survival, regeneration, and final retention in fat grafting. Plastic and reconstructive surgery. 2014;134(5):951-9.

122. Pan Z, Duan P, Liu X, Wang H, Cao L, He Y, et al. Effect of porosities of bilayered porous scaffolds on spontaneous osteochondral repair in cartilage tissue engineering. Regenerative biomaterials. 2015;2(1):9-19.

123. Lu W, Si YI, Ding J, Chen X, Zhang X, Dong Z, et al. Mesenchymal stem cells attenuate acute ischemia-reperfusion injury in a rat model. Experimental and therapeutic medicine. 2015;10(6):2131-7. 124. van Harmelen V, Skurk T, Hauner H. Primary culture and differentiation of human adipocyte precursor cells. Methods in molecular medicine. 2005;107:125-35.

125. Yoshimura K, Asano Y, Aoi N, Kurita M, Oshima Y, Sato K, et al. Progenitor-enriched adipose tissue transplantation as rescue for breast implant complications. The breast journal. 2010;16(2):169-75. 126. Paik KJ, Zielins ER, Atashroo DA, Maan ZN, Duscher D, Luan A, et al. Studies in Fat Grafting: Part V. Cell-Assisted Lipotransfer to Enhance Fat Graft Retention Is Dose Dependent. Plastic and reconstructive surgery. 2015;136(1):67-75.

127. Yeh HY, Lin TY, Lin CH, Yen BL, Tsai CL, Hsu SH. Neocartilage formation from mesenchymal stem cells grown in type II collagen-hyaluronan composite scaffolds. Differentiation; research in biological diversity. 2013;86(4-5):171-83.

128. Jeong IH, Shetty AA, Kim SJ, Jang JD, Kim YJ, Chung YG, et al. Autologous collagen-induced chondrogenesis using fibrin and atelocollagen mixture. Cells, tissues, organs. 2013;198(4):278-88.

129. Scott MA, Nguyen VT, Levi B, James AW. Current methods of adipogenic differentiation of mesenchymal stem cells. Stem cells and development. 2011;20(10):1793-804.

130. Levi B, Nelson ER, Li S, James AW, Hyun JS, Montoro DT, et al. Dura mater stimulates human adipose-derived stromal cells to undergo bone formation in mouse calvarial defects. Stem cells (Dayton, Ohio). 2011;29(8):1241-55.

131. Levi B, James AW, Nelson ER, Hu S, Sun N, Peng M, et al. Studies in adipose-derived stromal cells: migration and participation in repair of cranial injury after systemic injection. Plastic and reconstructive surgery. 2011;127(3):1130-40.

132. Levi B, Hyun JS, Nelson ER, Li S, Montoro DT, Wan DC, et al. Nonintegrating knockdown and customized scaffold design enhances human adipose-derived stem cells in skeletal repair. Stem cells (Dayton, Ohio). 2011;29(12):2018-29.

133. Memon B, Karam M, Al-Khawaga S, Abdelalim EM. Enhanced differentiation of human pluripotent stem cells into pancreatic progenitors co-expressing PDX1 and NKX6.1. Stem cell research \& therapy. 2018;9(1):15.

134. Sivan U, Jayakumar K, Krishnan LK. Matrix-directed differentiation of human adipose-derived mesenchymal stem cells to dermal-like fibroblasts that produce extracellular matrix. Journal of tissue engineering and regenerative medicine. 2016;10(10):E546-e58. 
135. Sivan U, Jayakumar K, Krishnan LK. Constitution of fibrin-based niche for in vitro differentiation of adipose-derived mesenchymal stem cells to keratinocytes. BioResearch open access. 2014;3(6):339-

47.

136. Fullgrabe A, Joost S, Are A, Jacob T, Sivan U, Haegebarth A, et al. Dynamics of Lgr6(+) Progenitor Cells in the Hair Follicle, Sebaceous Gland, and Interfollicular Epidermis. Stem cell reports.

2015;5(5):843-55.

137. Rubio D, Garcia-Castro J, Martin MC, de la Fuente R, Cigudosa JC, Lloyd AC, et al. Spontaneous human adult stem cell transformation. Cancer research. 2005;65(8):3035-9.

138. Ning $\mathrm{H}$, Yang $\mathrm{F}$, Jiang $\mathrm{M}, \mathrm{Hu}$ L, Feng $\mathrm{K}$, Zhang J, et al. The correlation between cotransplantation of mesenchymal stem cells and higher recurrence rate in hematologic malignancy patients: outcome of a pilot clinical study. Leukemia. 2008;22(3):593-9.

139. Kucerova L, Matuskova M, Hlubinova K, Altanerova V, Altaner C. Tumor cell behaviour modulation by mesenchymal stromal cells. Molecular cancer. 2010;9:129.

140. Mishra PJ, Mishra PJ, Humeniuk R, Medina DJ, Alexe G, Mesirov JP, et al. Carcinoma-associated fibroblast-like differentiation of human mesenchymal stem cells. Cancer research. 2008;68(11):4331-9.

141. Karnoub AE, Dash AB, Vo AP, Sullivan A, Brooks MW, Bell GW, et al. Mesenchymal stem cells within tumour stroma promote breast cancer metastasis. Nature. 2007;449(7162):557-63.

142. Mendicino M, Bailey AM, Wonnacott K, Puri RK, Bauer SR. MSC-based product characterization for clinical trials: an FDA perspective. Cell stem cell. 2014;14(2):141-5.

143. Gir P, Oni G, Brown SA, Mojallal A, Rohrich RJ. Human adipose stem cells: current clinical applications. Plastic and reconstructive surgery. 2012;129(6):1277-90.

144. Kellathur SN, Lou HX. Cell and tissue therapy regulation: worldwide status and harmonization. Biologicals : journal of the International Association of Biological Standardization. 2012;40(3):222-4.

145. Hayakawa T, Harris I, Joung J, Kanai N, Kawamata S, Kellathur S, et al. Report of the International Regulatory Forum on Human Cell Therapy and Gene Therapy Products. Biologicals : journal of the International Association of Biological Standardization. 2016;44(5):467-79.

146. Lee JE, Kim I, Kim M. Adipogenic differentiation of human adipose tissue-derived stem cells obtained from cryopreserved adipose aspirates. Dermatologic surgery : official publication for American Society for Dermatologic Surgery [et al]. 2010;36(7):1078-83. 